\title{
Best wishes for the New Year, and upcoming changes at Pediatric Nephrology
}

\author{
Michel Baum
}

Published online: 23 October 2010

(C) IPNA 2010

The editors of Pediatric Nephrology take this opportunity to wish you and your families a Happy Holiday and best wishes for the New Year. As we look toward the New Year, there are changes that are occurring in the Journal. First and most importantly, Otto Mehl's term as editor has come to an end. Otto has been responsible for bringing the Journal to a level of which we can all be proud. Under his guidance, the impact factor has more than doubled. He has been a guiding force for not only the Journal but for the International Pediatric Nephrology Association and nephrology in general.

On a personal note, we have been honored and privileged to work with one of the most brilliant minds in our subspecialty. Otto is not only an intellectual giant, but also a gentleman whom we are honored to call our friend. He will very much be missed. The new co-editor will be Lesley Rees, who should be congratulated and thanked for taking on this important role. We will also say farewell to some of our educational and review editors, including
Patrick Niaudet, Fredrick Kaskel, and Robert Mak. They have been responsible for many of the educational reviews and review articles that we have all enjoyed and have been responsible for the success of the Journal. We make these changes to increase the diversity of the Journal. We welcome Carl Bates, Rukshana Shroff, and Mark Mitsnefes as new teaching editors. Allison Eddy will continue to be editor for our review articles and will be joined by Detlef Bockenhauer and Prasad Devarajan. We hope you will enjoy their contributions.

We also take this opportunity to thank our editorial review board for their work and for maintaining the high standards of the Journal. We also thank the many manuscript contributors and journal reviewers. Please feel free to contact us if you have any ideas for reviews or if you think there is anything we can do to improve the Journal.

Sincerely,

Michel Baum and Lesley Rees

M. Baum $(\square)$

Pediatric Nephrology,

University of Texas Southwestern Medical Center,

5323 Harry Hines Blvd,

Dallas, TX 75390-9063, USA

e-mail: michel.baum@utsouthwestern.edu 